\title{
Having lunch at a staff canteen is associated with recommended food habits
}

\author{
Eva Roos*, Sirpa Sarlio-Lähteenkorva and Tea Lallukka \\ Department of Public Health, PO Box 41, 00014 University of Helsinki, Finland
}

Submitted 4 March 2003: Accepted 25 June 2003

\begin{abstract}
Objective: To describe the characteristics of employees having lunch at staff canteens and to examine the association between workplace lunch and recommended food habits.

Design: A mailed questionnaire including data on lunch pattern, food habits, sociodemographic background, work-related factors and body weight. Logistic regression models including food habits as dependent variables and lunch pattern, sociodemographic factors, work-related factors and body mass index as independent variables.

Setting: Helsinki Health Study survey data, collected in spring 2001.

Subjects: Employees from the City of Helsinki reaching 40, 45, 50, 55 and 60 years. The data included 2474 women and 591 men; the response rate was 68\%.

Results: About half of those with a staff canteen at work had lunch there. Those with higher educational level were more likely to have lunch at the staff canteen, as also were women with pre-school children and normal-weight men. Those having lunch at staff canteens were more likely to follow recommended food habits, compared with other subjects. Having lunch at the staff canteen seemed to increase the consumption frequency of vegetables and fish.

Conclusions: Having lunch at staff canteens is associated with the quality of the diet. To serve a cooked meal including vegetables during working time may be an efficient way to improve diet among adult employees. More emphasis should be put on increasing the possibility for employees to have lunch at staff canteens.
\end{abstract}

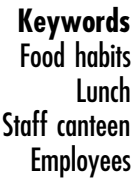

Keywords

Lunch

Employees
Eating outside the home is increasing all the time in the Western world. American studies show that the consumption of food prepared away from home increased from $18 \%$ of total energy in $1977-78$ to $32 \%$ in $1994-96$ in a population sample aged 2 years and over ${ }^{1,2}$ and from $29 \%$ to $47 \%$ among young adults aged 19-29 years ${ }^{3}$. The consumption of fast food and food prepared at restaurants has especially increased, but so too has the consumption of foods bought from stores but not eaten at home $e^{1,3}$. Several reasons can explain the increased consumption of food eaten away from home, such as women's higher involvement in the labour force, higher family incomes, smaller households and a higher supply of affordable and convenient fast-food outlets ${ }^{1}$.

Studies from different parts of the world have shown that foods outside the home contribute to unhealthy diets. American take-away food is highly dense in fat and saturated fat, and snacks and meals prepared outside the home contain more energy per eating occasion ${ }^{2}$. Americans who often eat at fast-food restaurants have higher energy and fat intakes and also greater body weight ${ }^{4-7}$. An Australian study showed that those getting a high proportion of their total energy intake from foods eaten outside the home also have higher fat and alcohol intakes $^{8}$. In addition, a French study showed that foods and drinks consumed outside the home are on average too rich in fat and protein?

According to Nielsen and colleagues ${ }^{3}$, greater attention must be paid to food consumed away from home and snacking when shifting the composition of the diet towards more healthful food choices. To improve the diet, healthy food choices outside the home need to be as readily available as the foods that have increased in popularity (pizza, cheeseburgers and salty snacks) over the past 20 years. Too few studies have focused on ways to improve food selection outside the home and more research is needed in this field ${ }^{6}$.

Workplaces are one of the key channels for interventions designed to improve health or reduce the risk of chronic diseases among adult populations ${ }^{10}$. In workplaces, staff canteens are of central importance, because it is possible to supply healthy food that is well-balanced according to modern guidelines. Modern canteen catering can also influence general attitudes to food ${ }^{6,11}$. A Finnish 
study of full-time employed women suggested that having lunch at the staff canteen improves food habits, and that the food served at the staff canteen may serve as a model of an optimal diet ${ }^{12}$.

Finland is a country with a long tradition of having staff canteens. The supply of staff canteens has been high, partly due to the high participation rate of women in the labour force in the post-war period. Social and health policy in Finland has supported staff canteens by subsidies, and national dietary guidelines for staff canteens have also been given ${ }^{13}$. Recommendations for workplace lunches in Finland were developed in the 1970s, and meal provision at work was included in trade union agreements in both public and private sectors.

In 1991, Finnish catering services served on average 0.4 meals per day per person. Staff canteens accounted for $11 \%$ of these meals served ${ }^{14}$. In 1997 , about $22 \%$ of $25-64-$ year-old men and women had their lunch at the staff canteen during workdays and only $7 \%$ of men and $2 \%$ of women had their lunch at another restaurant or café. On the other hand, $26 \%$ of women and $18 \%$ of men ate a packed lunch during lunchtime ${ }^{15}$.

The lunch served at Finnish staff canteens is typically a cooked hot meal including components such as meat, fish, potatoes, rice, pasta and milk. Both bread and fresh vegetables are normally included in the price.

Even if staff canteens offering healthy foods have been common for over 50 years in Finland, very few studies have been carried out to investigate their impact on the daily diet. Some population studies show that those having lunch at staff canteens eat more healthily than do others $^{16,17}$. Based on these population studies it is not possible to draw conclusions on the impact of workplace catering on the daily diet among employees, because data also include those without access to staff canteens and those not involved in the workforce such as the unemployed and housewives.

The aim of the present study was to describe the characteristics of employees who have lunch at staff canteens and to find out whether there is an association between having lunch at the staff canteen and recommended food habits. We also wanted to examine the association between lunch pattern and recommended food habits when other possible factors, such as socioeconomic and work-related factors, are taken into account. An additional aim was to determine possible gender differences in the associations between lunch pattern and recommended food habits.

\section{Data and methods}

This study is part of the ongoing Helsinki Health Study. The data derive from a postal survey in 2001. In spring 2001, a baseline questionnaire was mailed to 40-60-yearold employees from the City of Helsinki, born in 1941, 1946, 1951, 1956 or 1961. In all 4525 questionnaires were sent, of which 3065 (men 591, women 2474) were returned, giving a response rate of $68 \%$. Analysis of the non-response bias of similar data collected in 2000 in the Helsinki Health Study indicated that the data satisfactorily represented the target population ${ }^{18}$. Older men had a higher response rate than younger men. Upper white collar employees participated more actively than did other employees. The year 2001 data were collected in a similar way, so we assume that the same conclusions can be drawn for the data used in this study.

\section{Having lunch at the staff canteen}

The questionnaire included a following question: 'Do you have a staff canteen at your workplace?' The answer categories were (1) yes; (2) no, but available staff canteen is nearby; and (3) no. If the answer was 'yes' the respondent was classified as an employee with a staff canteen at work. Those with missing data on a staff canteen were excluded from the analyses (six men, 21 women).

The location of lunch place was measured by following question: 'Where do you usually have your lunch?' The answer categories were (1) at the staff canteen; (2) somewhere else at the workplace (e.g. in the coffee room); (3) in a restaurant or café; (4) somewhere else than previously mentioned locations; and (5) I don't have lunch. All who chose the first alternative were classified as having lunch at the staff canteen. Those with missing data on location of lunch place were excluded from the analyses (14 men, 56 women).

\section{Recommended food habits}

Consumption of various food items was measured by a food frequency inventory. Participants were asked what type of fat they use on bread and in food cooking. They were also asked to estimate how often they had eaten selected food items during the past 4 weeks, using the following seven alternatives: not during the past 4 weeks, 1-3 times a month, once a week, 2-4 times a week, 5-6 times a week, once a day or several times a day. The proportion of missing data varied between 1 and 5\%. The proportion of missing data was higher for food items consumed more seldom. The different categories were re-coded into frequency of food use during one month by the following frequencies: $0,2,4,12,22,28$ and 56, respectively. Missing data was coded as 0 .

The current Finnish dietary guidelines on recommended food intake were used to assess recommended food habits ${ }^{19}$. Based on these national guidelines, three separate indicators of recommended food habits were constructed from the food frequency inventory: eating vegetables more than once daily, eating fish at least twice a week and a summary index of recommended food habits.

The frequency of use during one month of cooked and fresh vegetables was summed up and if the frequency sum 
exceed 43 times per month, the respondent was classified as having vegetables more than once daily.

Those who reported a frequency of use of fish per month equal to 8 or higher were classified as having fish at least twice a week.

The summary index of recommended food habits consisted of six different items: eating fresh fruits or berries daily, eating fresh vegetables daily, having fish at least twice a week, eating dark bread such as rye bread daily, using oil in cooking and baking, and using margarine on bread. Every item fulfilled was scored 1 and respondents with a score of 5 or 6 were classified as following recommended food habits.

\section{Sociodemographic variables}

Food habits are determined by sociodemographic factors. Those with a higher educational level consume more vegetables and fruits and their food habits are closer to recommended food habits ${ }^{20-24}$. Also, family factors are associated with food habits. Married people follow a healthier diet than do single and previously married people ${ }^{21}$. To assess the independent association between lunch pattern and recommended food habits, sociodemographic variables including age, educational level, financial situation, marital status and parenting status were taken into account in the analyses.

The respondents were divided into three age groups: $40-45,50-55$ and 60 years.

The participants were divided based on educational level attained into three categories: primary (if they had basic education only), secondary (if vocational training or matriculation examination) and higher (if college or university examination).

The participants were divided into two groups based on their financial situation. They were asked to report how often they have enough money to buy necessary food and clothes for themselves and members of their family. Those who chose the alternatives 'always' or 'frequently' were classified as having enough money to spend on food and clothes.

Marital status was categorised into the following two groups: (1) cohabiting or married; and (2) single, including never married, divorced and widowed.

The participants were divided into two groups based on dependent pre-school children (under 7 years of age) or schoolchildren ( 7 to 18 years of age) in the household: none; or at least one dependent pre-school or schoolchild.

\section{Work-related factors}

Since the study was based on data of employees, we also wanted to take into account work-related factors that could possibly determine lunch pattern or food habits. If a person has a limited amount of time at work, he/she may eat a packed lunch instead of going to the canteen. If a person doesn't like to be at work or is being bullied at work, he/she may prefer not to go to the canteen. We therefore also examined work schedule, time for work tasks, control over work tasks and being bullied at work.

Work schedule was measured by following question: 'What is your present work mainly?' Response categories were (1) regular day work; (2) regular night work; (3) shift work without night work; (4) shift work with night work; (5) day work with occasional night work duty; and (6) something else. Those who answered in categories 1 and 5 were classified as having regular day work.

Those who disagreed with the statement 'I have enough time to do my work tasks' were classified as not having enough time for own work tasks.

Those who agreed with the statement 'I have very little freedom to decide how I do my work' were classified as not being able to control their work tasks.

Bullying was asked by following question: 'Have you ever been bullied?' Those who chose the answer alternative 'Yes, at the moment' were classified as being bullied at that moment.

\section{Body mass index}

Body mass index (BMI) was also included in the analyses, because fatness might influence willingness to have lunch at a staff canteen and body weight can be associated with food habits.

BMI $\left(\mathrm{kg} \mathrm{m}^{-2}\right)$ was calculated using self-reported information about current weight and height. All persons whose BMI was above $25 \mathrm{~kg} \mathrm{~m}^{-2}$ were classified as overweight.

\section{Statistical methods}

The SPSS statistical package (SPSS, Inc., Chicago, IL, USA) was used for all analyses. The analyses were carried out separately for men and women because of the known gender differences in food habits. We also wanted to determine possible gender differences in having lunch at staff canteens and in the association between having lunch at a staff canteen and food habits.

The total data were used in the description of those with a staff canteen at their workplace and those having lunch at a staff canteen. In further analyses, where we investigated the association between having lunch at staff canteens and food habits, we used restricted data. We excluded all who reported not having a staff canteen at their workplace (851 women and 162 men excluded) and those who reported not doing regular day work (additionally 353 women and 100 men excluded). The restricted data consisted of 329 men and 1270 women.

We calculated the proportion of respondents having a staff canteen at work according to sociodemographic variables (Table 1). We also calculated the distribution of lunch eating pattern according to whether the respondents had a staff canteen at work, one near to work or if they had no access to a staff canteen. These analyses were carried out with the total data. 
With the restricted data we calculated the mean frequency of use of the foods consumed in the last month in the different lunch pattern groups (Table 3 ).

The restricted data were also used in the logistic regression analyses that we carried out to examine the determinants of the variables having lunch at a staff canteen, eating vegetables more than once daily, eating fish at least twice a week and following recommended food habits (Tables 2 and 4) .

Sociodemographic factors, work-related factors and BMI were included as independent variables in the models of Table 2, as was also having lunch at a staff canteen in Table 4. Simple models in Table 4 included only one independent variable at a time whereas full models were constructed so that all independent variables were included at the same time. Results from logistic regression models are presented as odds ratios with 95\% confidence intervals, where one category of each variable serves as a reference category that receives the value of 1.00. In other words, the simple models show the unadjusted associations and the full models show the associations that are adjusted for all other independent variables. If data were missing the observation was excluded from the analyses.

\section{Results}

The majority of this study's employees, $74 \%$ of men and $67 \%$ of women, had a staff canteen at their workplace, and
$43 \%$ of all men and $34 \%$ of all women reported that they usually had lunch at the staff canteen.

Table 1 describes the proportion of employees with a staff canteen at their workplace according to different sociodemographic variables and to regularity in working day. In men, a higher proportion of those with regular day work had a staff canteen at their workplace. An opposite association was found for women: the proportion was lower for those with regular day work compared with those with no regular day work. Also, a higher proportion of older women, women with no schoolchildren and women with higher educational level had a staff canteen at work compared with other groups.

The presence of a staff canteen at work was clearly associated with having lunch at the staff canteen. Of those with a staff canteen at work, $54 \%$ of men and $48 \%$ of women had their lunch at the staff canteen. Equivalent numbers for those with a staff canteen only close to work were $28 \%$ for men and $21 \%$ for women. The second most common lunch pattern was eating packed lunch; 19\% of men and 39\% of women with a staff canteen at work ate packed lunch. Equivalent numbers for those having a staff canteen close to the workplace were $31 \%$ for men and $60 \%$ for women. The proportions eating packed lunch of people with no staff canteen at work or close to work were $60 \%$ for men and $70 \%$ for women. About $15 \%$ of men and $10 \%$ of women did not eat lunch at all, and $<5 \%$ of men and $<2 \%$ of women had their lunch at another restaurant or café.

Table 1 Distribution of background factors and proportion of employees who have a staff canteen at work, according to sociodemographic factors and work regularity

\begin{tabular}{|c|c|c|c|c|}
\hline & \multicolumn{2}{|c|}{ Men $(n=591)$} & \multicolumn{2}{|c|}{ Women $(n=2474)$} \\
\hline & $\begin{array}{l}\text { Distribution } \\
(\%)\end{array}$ & $\begin{array}{c}\text { Have staff canteen } \\
\text { at work }(\%)\end{array}$ & $\begin{array}{l}\text { Distribution } \\
(\%)\end{array}$ & $\begin{array}{c}\text { Have staff canteen } \\
\text { at work }(\%)\end{array}$ \\
\hline Age (years) & & $P=0.58$ & & $P=0.00$ \\
\hline $40-45$ & 38 & 72 & 42 & 62 \\
\hline $50-55$ & 47 & 74 & 45 & 70 \\
\hline 60 & 15 & 78 & 13 & 71 \\
\hline Missing & 0 & & 0 & \\
\hline Marital status & & $P=0.93$ & & $P=0.22$ \\
\hline Single & 22 & 74 & 34 & 65 \\
\hline Married or cohabiting & 77 & 74 & 66 & 68 \\
\hline Missing & 1 & & 0.6 & \\
\hline Pre-school children & & $P=0.58$ & & $P=0.37$ \\
\hline No or missing & 87 & 74 & 90 & 67 \\
\hline Yes & 13 & 71 & 10 & 64 \\
\hline Schoolchildren & & $P=0.96$ & & $P=0.01$ \\
\hline No or missing & 67 & 74 & 60 & 69 \\
\hline Yes & 33 & 74 & 40 & 64 \\
\hline Educational level & & $P=0.27$ & & $P=0.00$ \\
\hline Primary & 40 & 71 & 43 & 64 \\
\hline Secondary & 30 & 74 & 32 & 64 \\
\hline Higher & 30 & 78 & 24 & 75 \\
\hline Missing & 0.2 & & 0.6 & \\
\hline Enough money for food and clothes & & $P=0.89$ & & $P=0.71$ \\
\hline No & 15 & 74 & 16 & 66 \\
\hline Yes & 84 & 74 & 83 & 67 \\
\hline Missing & 1 & & 1 & \\
\hline Regular day work & & $P=0.007$ & & $P=0.03$ \\
\hline No or missing & 30 & 66 & 22 & 71 \\
\hline Yes & 70 & 77 & 78 & 66 \\
\hline
\end{tabular}


Table 2 describes the association of sociodemographic, work-related background factors and overweight with having lunch at a staff canteen. The data were restricted to only those people with a staff canteen at their workplace. High educational level was associated with having lunch at a staff canteen among both men and women. Work-related factors were not associated with having lunch at a staff canteen. Men with normal weight were more likely to have lunch at the staff canteen than were men with BMI $>25 \mathrm{~kg} \mathrm{~m}^{-2}$. Women with pre-school children were also more likely to have lunch at a staff canteen than were women with no pre-school children in the household.

Table 3 describes the frequency of food consumption during the past month. The consumption frequency was higher among those having lunch at a staff canteen compared with others for the following food items: rice and pasta, potatoes, fresh vegetables, cooked vegetables, fish, chicken (women only) and juice (women only). The consumption was lower for wheat bread among men and for eggs among women.

Those who had lunch at a staff canteen were more likely to follow recommended food habits. The odds ratios and 95\% confidence intervals for consuming vegetables more than once daily for men was 2.22 (1.37-3.60) and for women $1.73(1.36-2.21)$, when comparing those having lunch at a staff canteen with those not having lunch at a staff canteen. The equivalent values for eating fish at least twice a week were $2.37(1.48-3.80)$ for men and 1.59 (1.26-1.99) for women. Table 4 shows that those having lunch at a staff canteen more often had food habits that followed the national dietary guidelines. The associations
Table 2 Odds ratios and 95\% confidence intervals for eating lunch at the staff canteen, for those having a staff canteen at work and doing regular day work. All variables included simultaneously

\begin{tabular}{|c|c|c|}
\hline & $\begin{array}{c}\text { Men } \\
(n=319)\end{array}$ & $\begin{array}{c}\text { Women } \\
(n=1179)\end{array}$ \\
\hline \multicolumn{3}{|l|}{ Age (years) } \\
\hline $40-45$ & 1.00 & 1.00 \\
\hline $50-55$ & $0.70(0.37-1.31)$ & $1.08(0.80-1.44)$ \\
\hline 60 & $1.10(0.49-2.47)$ & $0.70(0.46-1.07)$ \\
\hline \multicolumn{3}{|l|}{ Marital status } \\
\hline Single & 1.00 & 1.00 \\
\hline Married or cohabiting & $1.27(0.67-2.40)$ & $0.79(0.60-1.02)$ \\
\hline \multicolumn{3}{|l|}{ Pre-school children } \\
\hline No & 1.00 & 1.00 \\
\hline Yes & $0.91(0.36-2.30)$ & $1.60(1.01-2.55)$ \\
\hline \multicolumn{3}{|l|}{ Schoolchildren } \\
\hline No & 1.00 & 1.00 \\
\hline Yes & $1.38(0.79-2.43)$ & $0.81(0.61-1.07)$ \\
\hline \multicolumn{3}{|l|}{ Educational level } \\
\hline Primary & 1.00 & 1.00 \\
\hline Secondary & $1.77(0.94-3.34)$ & $1.60(1.19-2.14)$ \\
\hline Higher & $2.46(1.33-4.55)$ & $2.52(1.86-3.41)$ \\
\hline \multicolumn{3}{|c|}{ Enough money for food and clothes } \\
\hline No & 1.00 & 1.00 \\
\hline Yes & $1.80(0.89-3.64)$ & $1.30(0.92-1.83)$ \\
\hline \multicolumn{3}{|l|}{ Time for work tasks } \\
\hline Enough & 1.00 & 1.00 \\
\hline Not enough & $1.42(0.84-2.38)$ & $1.00(0.78-1.27)$ \\
\hline \multicolumn{3}{|c|}{ Freedom to decide how to do work tasks } \\
\hline Freedom & 1.00 & 1.00 \\
\hline No freedom & $0.69(0.32-1.48)$ & $1.06(0.73-1.54)$ \\
\hline \multicolumn{3}{|c|}{ Bullied at work at the moment? } \\
\hline No & 1.00 & 1.00 \\
\hline Yes & $1.44(0.57-3.68)$ & $1.00(0.60-1.65)$ \\
\hline \multicolumn{3}{|c|}{ Body mass index $<25 \mathrm{~kg} \mathrm{~m}^{-2}$} \\
\hline No & 1.00 & 1.00 \\
\hline Yes & $3.33(1.94-5.70)$ & $1.20(0.94-1.52)$ \\
\hline
\end{tabular}

Table 3 Frequency of use of food items during the previous four weeks for those having a staff canteen at work and doing regular day work. One-way analysis of variance

\begin{tabular}{|c|c|c|c|c|c|c|}
\hline & \multicolumn{3}{|c|}{ Men $(n=319)$} & \multicolumn{3}{|c|}{ Women $(n=1179)$} \\
\hline & $\begin{array}{l}\text { Has lunch at } \\
\text { staff canteen }\end{array}$ & $\begin{array}{l}\text { Does not have lunch } \\
\text { at staff canteen }\end{array}$ & $P$-value & $\begin{array}{l}\text { Has lunch at } \\
\text { staff canteen }\end{array}$ & $\begin{array}{l}\text { Does not have lunch } \\
\text { at staff canteen }\end{array}$ & $P$-value \\
\hline Fatty cheeses & 13.7 & 12.1 & 0.34 & 12.2 & 12.7 & 0.58 \\
\hline Low-fat cheeses & 8.5 & 7.9 & 0.72 & 13.1 & 12.6 & 0.59 \\
\hline Porridge, cereals & 12.2 & 9.6 & 0.05 & 11.6 & 11.9 & 0.64 \\
\hline Rice, pasta & 7.5 & 5.8 & 0.01 & 7.7 & 6.4 & 0.000 \\
\hline Rye bread & 32.5 & 29.5 & 0.17 & 35.3 & 37.2 & 0.06 \\
\hline Wheat bread & 16.8 & 23.4 & 0.000 & 22.1 & 21.1 & 0.27 \\
\hline White bread & 4.4 & 5.9 & 0.15 & 2.5 & 3.1 & 0.15 \\
\hline Potatoes & 17.4 & 14.8 & 0.015 & 17.6 & 15.2 & 0.000 \\
\hline Fresh vegetables & 29.0 & 22.6 & 0.000 & 34.2 & 29.9 & 0.000 \\
\hline Cooked vegetables & 14.2 & 11.5 & 0.02 & 20.8 & 16.9 & 0.000 \\
\hline Fruits and berries & 21.2 & 19.4 & 0.23 & 30.0 & 30.9 & 0.37 \\
\hline Fish & 8.0 & 5.9 & 0.000 & 8.0 & 6.8 & 0.000 \\
\hline Chicken & 6.9 & 6.2 & 0.24 & 7.6 & 6.6 & 0.001 \\
\hline Meat & 13.9 & 15.4 & 0.20 & 11.1 & 12.2 & 0.08 \\
\hline Eggs & 4.2 & 5.1 & 0.13 & 3.3 & 3.9 & 0.02 \\
\hline Sweet snacks & 11.6 & 11.0 & 0.61 & 12.6 & 11.9 & 0.29 \\
\hline High-fat milk & 2.9 & 2.1 & 0.43 & 1.2 & 1.3 & 0.65 \\
\hline Low-fat or skimmed milk & 21.8 & 22.9 & 0.85 & 20.8 & 21.2 & 0.73 \\
\hline Sour milk & 6.6 & 5.5 & 0.38 & 10.8 & 10.1 & 0.47 \\
\hline Juices & 17.5 & 17.6 & 0.96 & 18.3 & 15.8 & 0.007 \\
\hline Coffee & 41.8 & 42.2 & 0.85 & 43.8 & 42.9 & 0.42 \\
\hline Tea & 15.4 & 12.5 & 0.16 & 16.9 & 17.3 & 0.73 \\
\hline
\end{tabular}


Table 4 Odds ratios and 95\% confidence intervals for having food habits that follow national dietary guidelines for those having a staff canteen at work and doing regular day work

\begin{tabular}{|c|c|c|c|c|}
\hline & \multicolumn{2}{|c|}{$\operatorname{Men}(n=318)$} & \multicolumn{2}{|c|}{ Women $(n=1173)$} \\
\hline & Single model & Full model & Single model & Full model \\
\hline \multicolumn{5}{|c|}{ Having lunch at a staff canteen } \\
\hline No & 1.00 & 1.00 & 1.00 & 1.00 \\
\hline Yes & $2.14(1.16-3.92)$ & $2.05(1.06-3.98)$ & $1.53(1.19-1.97)$ & $1.42(1.08-1.85)$ \\
\hline \multicolumn{5}{|l|}{ Age (years) } \\
\hline $40-45$ & 1.00 & 1.00 & 1.00 & 1.00 \\
\hline $50-55$ & $1.77(0.91-3.44)$ & $1.65(0.75-3.66)$ & $1.61(1.23-2.11)$ & $2.16(1.54-3.03)$ \\
\hline 60 & $1.50(0.67-3.40)$ & $1.32(0.49-3.55)$ & $1.39(0.95-2.04)$ & $2.03(1.27-3.25)$ \\
\hline \multicolumn{5}{|l|}{ Marital status } \\
\hline Married or cohabiting & 1.00 & 1.00 & 1.00 & 1.00 \\
\hline Single & $1.55(0.74-3.23)$ & $1.26(0.56-2.85)$ & $1.45(1.11-1.91)$ & $1.38(1.03-2.36)$ \\
\hline \multicolumn{5}{|l|}{ Pre-school children } \\
\hline No & 1.00 & 1.00 & 1.00 & 1.00 \\
\hline Yes & $0.71(0.26-1.90)$ & $0.92(0.29-2.93)$ & $0.89(0.57-1.37)$ & $1.16(0.69-1.94)$ \\
\hline \multicolumn{5}{|l|}{ Schoolchildren } \\
\hline No & 1.00 & 1.00 & 1.00 & 1.00 \\
\hline Yes & $1.00(0.56-1.78)$ & $0.99(0.51-1.90)$ & $0.98(0.76-1.26)$ & $1.15(0.84-1.56)$ \\
\hline \multicolumn{5}{|l|}{ Educational level } \\
\hline Primary & 1.00 & 1.00 & 1.00 & 1.00 \\
\hline Secondary & $0.87(0.42-1.80)$ & $0.65(0.29-1.43)$ & $1.67(1.23-2.26)$ & $1.57(1.12-2.19)$ \\
\hline Higher & $1.14(0.59-2.21)$ & $0.85(0.41-1.75)$ & $1.67(1.24-2.26)$ & $1.44(1.03-2.03)$ \\
\hline \multicolumn{5}{|c|}{ Enough money for food and clothes } \\
\hline No & 1.00 & 1.00 & 1.00 & 1.00 \\
\hline Yes & $2.31(0.88-6.09)$ & $1.91(0.69-5.31)$ & $2.02(1.36-2.99)$ & $1.55(1.03-2.36)$ \\
\hline \multicolumn{5}{|l|}{ Time for work tasks } \\
\hline Not enough & 1.00 & 1.00 & 1.00 & 1.00 \\
\hline Enough & $1.25(0.71-2.19)$ & $1.21(0.67-2.20)$ & $1.09(0.85-1.39)$ & $1.06(0.81-1.39)$ \\
\hline \multicolumn{5}{|c|}{ Freedom to decide how to do work tasks } \\
\hline No freedom & 1.00 & 1.00 & 1.00 & 1.00 \\
\hline Freedom & $1.20(0.52-2.77)$ & $1.21(0.50-2.92)$ & $0.85(0.58-1.25)$ & $0.91(0.59-1.38)$ \\
\hline \multicolumn{5}{|c|}{ Bullied at work at the moment? } \\
\hline Yes & 1.00 & 1.00 & 1.00 & 1.00 \\
\hline \multirow{2}{*}{\multicolumn{5}{|c|}{ Body mass index $<25 \mathrm{~kg} \mathrm{~m}^{-2}$}} \\
\hline & & & & \\
\hline No & 1.00 & 1.00 & 1.00 & 1.00 \\
\hline Yes & $1.29(0.74-2.26)$ & $1.09(0.59-1.99)$ & $1.06(0.82-1.35)$ & $1.01(0.78-1.32)$ \\
\hline
\end{tabular}

remained statistically significant even when adjusted for other possible factors among both men and women. Among men, having lunch at a staff canteen was the only determinant that remained associated with the studied food habits in the fully adjusted models. Among women, also age, marital status, educational level and having enough money for food and clothes remained associated with recommended food habits. Women in the age group 50-55 years, married women, women with more than primary educational level and women having enough money for food and clothes were more likely to follow recommended food habits than were other women.

\section{Discussion}

The aim of this study was to describe the characteristics of those having lunch at staff canteens and to examine the association between lunch pattern and recommended food habits. The main findings in this study are the following. About half of those with a staff canteen at their workplace had their lunch at there. Those with higher educational level, women with pre-school children and men with normal weight were more likely to have lunch at staff canteens. Those who had lunch at staff canteens were more likely to follow recommended food habits compared with others.

This study shows that more than a third of employees in the City of Helsinki had lunch at a staff canteen. When a staff canteen existed at the workplace, then every other person had lunch at the staff canteen. Having lunch at a staff canteen was previously even more popular in Finland. The proportion of employees who had lunch at a staff canteen was highest in 1987. Economic depression in the 1990s diminished the support given to workplace catering by employers and the state $e^{13}$. This reduced the number of employees having lunch at staff canteens; for example, among state employees, the prevalence of having lunch at the staff canteen decreased from 50\% to 30\% between 1982 and $1992^{13}$. Our study shows a higher prevalence of having lunch at the staff canteen than among state employees in 1992. This can be explained by regional differences in lunch eating patterns, because having lunch at the staff canteen is much more common in the Helsinki region than in other parts of Finland ${ }^{15}$. 
Those with higher educational level were more likely to have their lunch at a staff canteen. Several possible explanations can be suggested for this finding, such as the well educated being more health-oriented concerning $\operatorname{diet}^{22,24}$, better able to afford to having lunch at a canteen and more accustomed to having a lunch prepared outside the home during lunchtime.

The association between educational level and having lunch at a staff canteen was adjusted for income (enough money for food and clothes) in the full model, but the association remained between educational level and lunch pattern. Adjusting for another type of income variable, such as household income, might have given a different result. A reduction in subsidies has in previous studies been associated with a decrease in meals at staff canteens in both Finland and Sweden ${ }^{13,25}$. Lower income might therefore be a barrier to having lunch at a staff canteen when lunch prices are higher.

An interesting finding is that men who had lunch at staff canteens were less likely to be overweight. One possible explanation could be that snacks and other food eaten instead of canteen food contribute to fatness among men who were not having lunch at the staff canteen. Studies from other countries have shown that food eaten outside the home contributes to a less healthy diet ${ }^{2,4-9}$. The same association as for men could not be found for women. Women are more health-conscious ${ }^{26,27}$ and may therefore be more aware of what food they eat outside the home regardless of lunch pattern.

Unfortunately, we do not have any data concerning the packed lunch. Therefore we could not compare the diet of those who brought their food from home with those who had lunch at the workplace canteen or with those who bought their food from, e.g., grocery shops.

Women with pre-school children were more likely to have lunch at the staff canteen than were other women. We do not find any explanation for this finding. One reason might be that the women who still had pre-school children in this study population probably belonged to the youngest age group and were probably also more educated than the other women, and adjustment for these factors did not completely abolish this effect.

This study shows that those having lunch at staff canteens ate most of the studied food items more frequently. One reason might be that they actually ate more, but this is not plausible because they were not more overweight. We suggest that those who had lunch at staff canteens ate a more varied diet than did other subjects, and the variety caused higher frequencies, not the quantity of consumed food. However, total energy intake or amount of food consumed could not be examined because the questionnaire measured just frequencies, not quantities. Unfortunately we are not able to do any validity study of the food frequency inventory and food indices, although similar types of indices have been used in several other studies $^{28,29}$. We made assumptions of healthy diet based on the Finnish national dietary guidelines ${ }^{19}$. According to the guidelines, it is more preferable that people use margarine on bread and oil in cooking instead of butter. The dietary guidelines also recommend a daily intake of vegetables, fruits and dark bread.

Those having lunch at staff canteens seemed to have healthier food habits. Dietary guidelines for staff canteens are followed quite well and the lunches served at staff canteens can be regarded as healthy ${ }^{30}$. We can therefore assume that the food consumed at staff canteens is healthy. In addition, the food served during the lunches may serve as a model of an optimal meal. This can influence general attitude to foods and food choices during other eating occasions as well ${ }^{6,11,12}$. Indeed, another Finnish study of young adults showed that having lunch at a staff canteen was associated with a healthier $\operatorname{diet}^{17}$.

We find higher daily frequencies of vegetable consumption, but not frequency of fruit consumption, among those having lunch at staff canteens compared with others. Finns usually consume vegetables only during meals ${ }^{31}$. They are not consumed as snacks, which is the case with fruits. The lunch served in staff canteens always includes a free salad of fresh vegetables, so it seems reasonable that lunch at a staff canteen promotes the consumption of vegetables. Other studies also support the finding that having lunch at staff canteens promotes the consumption of vegetables ${ }^{16,17}$. However, we do not know if the participants ate their cooked vegetables as fried and whether fat was added or not.

It is likely that meals offered at staff canteens influence the opportunities of having fish regularly. Fish is usually seen as a food item requiring more skill and work to prepare than other food items. Staff canteens serve fish dishes regularly, which perhaps promotes the consumption of fish

The sample of this study is derived from employees in the City of Helsinki aged 40 years or more. The response rate was $68 \%$. According to the non-response analyses of the Helsinki Health Study, the data seem to be comparable with the target population ${ }^{18}$. This group also represents employees living in the capital region of Helsinki. From other studies we know that they more often have lunch at staff canteens than do employees from other parts of Finland ${ }^{15}$. The proportion of employees having lunch might therefore be a little higher than in other parts of Finland. However, the association between food habits and lunch pattern would probably be similar in other parts of Finland because all staff canteens in Finland have the same guidelines and the foods served in the staff canteens should not differ too much.

Fewer men than women took part in the present study, because only $20 \%$ of employees of the City of Helsinki are male. The small number of men in the analyses makes it difficult to achieve statistically significant results among men. 
In this study we used cross-sectional data, which means that it is impossible to know in which order the factors influence each other. Having lunch at a staff canteen may promote healthier food habits or the association could be the other way around: those who want to eat healthily also have their lunch at a staff canteen.

As mentioned above, eating outside the home is increasing all the time in the Western world ${ }^{1,2}$. It is of great importance to have healthy food choices outside the home as readily available as other alternatives. One way to do this is to ensure the availability and accessibility of healthy foods at work sites ${ }^{6}$. Staff canteens that follow dietary guidelines offer a good possibility to maintain and even promote healthy food habits among employees. This is especially important in societies where women take an active part in the labour force and less time is left for food preparation in the household. An increase in subsidies for meals served at staff canteens would probably increase the number of customers at staff canteens ${ }^{17}$.

\section{Conclusions}

This study showed that having lunch at staff canteens is associated with the quality of the diet. To serve a cooked meal including vegetables during working time may be an efficient way to improve diet among adult employees. This seems to be especially true in societies where women are more highly involved in the labour force. More emphasis should be put on increasing the possibility for employees to have lunch at a staff canteen.

\section{Acknowledgements}

The Helsinki Health Study is supported by grants from the Academy of Finland (nos. 45367, 48118, 52277 and 53245) and the Finnish Work Environment Fund (no. 99090). We thank the City of Helsinki, and all members of the Helsinki Health Study group.

\section{References}

1 Anon. Contribution of away-from-home foods to American diet quality. Family Economics and Nutrition Review 1999 12(3\&4): 85-9.

2 Guthri JF, Lin BH, Frazao E. Role of food prepared away from home in the American diet, 1977-78 versus 1994-96: changes and consequences. Journal of Nutrition Education and Behavior 2002; 34(3): 140-50.

3 Nielsen SJ, Siega-Riz AM, Popkin BM. Trends in food locations and sources among adolescents and young adults. Preventive Medicine 2002; 35(2): 107-13.

4 Haines PS, Hungerford DW, Popkin BM, Guilkey DK. Eating patterns and energy and nutrient intakes of US women. Journal of the American Dietetic Association 1992; 92(6): 698-704.

5 French SA, Harnack L, Jeffery RW. Fast food restaurant use among women in the Pound of Prevention study: dietary, behavioral and demographic correlates. International Journal of Obesity 2000; 24(10): 1353-9.
6 French SA, Story M, Jeffery RW. Environmental influences on eating and physical activity. Annual Review of Public Health 2001; 22: 309-35.

7 French SA, Story M, Neumark-Sztainer D, Fulkerson JA, Hannan P. Fast food restaurant use among adolescents: associations with nutrient intake, food choices and behavioral and psychosocial variables. International Journal of Obesity 2001; 25(12): 1823-33.

8 Burns C, Jackson M, Gibbons C, Stoney RM. Foods prepared outside the home: association with selected nutrients and body mass index in adult Australians. Public Health Nutrition 2002; 5(3): 441-8.

9 Le Francois P, Calamassi-Tran G, Hebel P, Renault C, Lebreton S, Volatier JL. Food and nutrient intake outside the home of 629 French people of fifteen years and over. European Journal of Clinical Nutrition 1996; 50(12): 826-31.

10 Emmons KM, Linnan LA, Shadel WG, Marcus B, Abrams DB. The Working Healthy Project: a worksite health-promotion trial targeting physical activity, diet, and smoking. Journal of Occupational and Environmental Medicine 1999; 41(7): 545-55.

11 Winter I, Ott-Gerlach G. Wholesome occupational food services - an area of prevention with high acceptance [in German]. Offentliche Gesundheitwesen 1991; 53: 44-7.

12 Mäkelä J. 'You should eat more salad'. Nutrition recommendations and women's views on healthy eating in Helsinki metropolitan area [in Finnish]. Journal of Social Medicine 1996; 33: 17-23.

13 Prättälä R. North European meals: observations from Denmark, Finland, Norway and Sweden. In: Meiselman HL, ed. Dimensions of the Meal. The Science, Culture, Business and Art of Eating. Maryland: Aspen Publications, 2000; 191-201.

14 National Nutrition Council. Nutrition Policy in Finland. Country paper prepared for the FAO/WHO International Conference on Nutrition, Rome, 1992; 11: 1-64.

15 National Public Health Institute. The 1997 Dietary Survey of Finnish Adults. Helsinki: National Public Health Institute, 1998; B8: $1-96$.

16 Lallukka T, Lahti-Koski M, Ovaskainen M. Vegetable and fruit consumption and its determinants in young Finnish adults. Scandinavian Journal of Nutrition 2001; 45: 120-5.

17 Laitinen J. Eating during work hours among young adults [in Finnish]. Work and Human 2000; 1: 49-67.

18 Lallukka T, Aittomäki A, Piha K, Roos E, Kivelä K, Silventoinen K. Associations of socio-economic factors and sickness absence with participation in a health survey [in Finnish]. Journal of Social Medicine 2002; 39: 164-71.

19 National Nutrition Council. Finnish Dietary Guidelines. Helsinki: National Nutrition Council, 1998; 7: 1-80 [in Finnish].

20 Roos E, Prättälä R, Lahelma E, Kleemola P, Pietinen P. Modern and healthy?: socioeconomic differences in the quality of diet. European Journal of Clinical Nutrition 1996; 50(11): 753-60.

21 Roos E, Lahelma E, Virtanen M, Prättälä R, Pietinen P. Gender, socioeconomic status and family status as determinants of food behaviour. Social Science \& Medicine 1998; 46(12): 1519-29.

22 Hulshof KF, Lowik MR, Kok FJ, Wedel M, Brants HA, Hermus RJ, et al. Diet and other life-style factors in high and low socio-economic groups (Dutch Nutrition Surveillance System). European Journal of Clinical Nutrition 1991; 45(9): 441-50.

23 Hulshof KF, Brussaard JH, Kruizinga AG, Telman J, Lowik MR. Socio-economic status, dietary intake and $10 \mathrm{y}$ trends: the Dutch National Food Consumption Survey. European Journal of Clinical Nutrition 2003; 57(1): 128-37. 
24 Shimakawa T, Sorlie P, Carpenter MA, Dennis B, Tell GS, Watson R, et al. Dietary intake patterns and sociodemographic factors in the Atherosclerosis Risk in Communities Study. ARIC Study Investigators. Preventive Medicine 1994; 23(6): 769-80.

25 Lennernäs M, Becker W, Hagman U. Matvanor före och efter beskattningen av lunchsubventionerna [ Food Habits Before and After the Taxation of Lunch Subsidies] Uppsala: SLV rapport, 1994; 4: 1-73.

26 Hayes D, Ross CE. Concern with appearance, health beliefs, and eating habits. Journal of Health and Social Behavior 1987; 28(2): 120-30.

27 Turrell G. Determinants of gender differences in dietary behavior. Nutrition Research 1997; 17: 1105-20.
28 Basiotis PP, Guthrie JF, Bowman SA, Welsh SO. Construction and evaluation of a diet status index. Family Economics and Nutrition Review 1995; 8: 2-13.

29 Kennedy E, Ohls J, Carlson S, Fleming K. The Healthy Eating Index: design and applications. Journal of the American Dietetic Association 1995; 95: 1103-8.

30 Hasunen K, Helminen P, Lusa S, Prättälä R. Yksin vai yhdessä? Työpaikkaruokailu murrosvaibeessa [Alone or Together? Having Lunch at Staff Canteens is in a Transition Period]. Helsinki: Työterveyslaitos, 1995.

31 Roos E, Prättälä R. Meal pattern and nutrient intake among adult Finns. Appetite 1997; 29(1): 11-24. 